\title{
Tetraspanin CD81 is an adverse prognostic marker in acute myeloid leukemia
}

\author{
Thomas Boyer ${ }^{1,2, *}$, Soizic Guihard ${ }^{2, *}$, Christophe Roumier $^{1}$, Pauline Peyrouze ${ }^{2}$, \\ Fanny Gonzales ${ }^{2}$, Céline Berthon ${ }^{2,3}$, Bruno Quesnel ${ }^{2,3}$, Claude Preudhomme ${ }^{1,2}$, \\ Hélène Behal ${ }^{5}$, Alain Duhamel ${ }^{5}$, Catherine Roche-Lestienne ${ }^{2,4}$, Meyling Cheok ${ }^{2}$ \\ ${ }^{1}$ Hematology Laboratory, Biology and Pathology Center, CHRU Lille, France \\ ${ }^{2}$ Jean-Pierre AUBERT Research Center, UMR-S1172, Lille, France \\ ${ }^{3}$ Department of Hematology, Claude Huriez Hospital, CHRU Lille, France \\ ${ }^{4}$ Institute of Medical Genetics, Jeanne de Flandre Hospital, CHRU Lille, France \\ ${ }^{5}$ Department of Biostatistics, Univ. Lille, CHU Lille, EA 2694 - Santé Publique: Épidémiologie et Qualité des Soins, F-59000 \\ Lille, France \\ *These authors have contributed equally to this work \\ Correspondence to: Meyling Cheok, email: meyling.cheok@inserm.fr
}

Keywords: acute myeloid leukemia, prognosis, CD81, tetraspanin, flow cytometry

Received: June 07, 2016

Accepted: July 28, 2016

Published: August 22, 2016

\section{ABSTRACT}

CD81 is a cell surface protein which belongs to the tetraspanin family. While in multiple myeloma its expression on plasma cells is associated with worse prognosis, this has not yet been explored in acute myeloid leukemia (AML). We measured membrane expression of CD81 on AML cells at diagnosis, evaluated its association with AML characteristics and its influence on patient outcome after intensive chemotherapy in a cohort of 134 patients. CD81 was detected in 92/134 (69\%) patients. Patients with AML expressing CD81 had elevated leukocyte count $(P=0.02)$ and were more likely classified as intermediate or adverse-risk by cytogenetics $(P<0.001)$. CD81 expression had a negative impact on survival (event-free survival, overall survival and relapse-free survival) in univariate $(P<0.001)$ and in multivariate analyses $(P=0.003$, 0.002 and $<0.001$, respectively). CD81 has a negative impact on OS in patients with NPM1 mutation $(P=0.01)$ and in patients ELN-favorable $(P=0.002)$. In conclusion, this cell surface marker may be a new prognostic marker for diagnostic risk classification and a potential therapeutic target for drug development in AML.

\section{INTRODUCTION}

CD81 antigen belongs to the tetraspanin family (33 members in mammals), which are cell surface transmembrane proteins. This antigen was originally discovered as a target of an antiproliferative antibody and subsequently named TAPA-1 [1]. It associates with other proteins in dynamic membrane entities called tetraspanin-enriched microdomains (TEMs) and partners may vary according to cell type (e.g., CD19 in $\mathrm{B}$ cells) [2]. Various cellular functions are linked to $\mathrm{CD} 81$ (i.e., BCR signaling in B cells [3], B-T cell interaction [4] and cell entry receptor function for different infectious diseases [5]). Furthermore, recent studies showed that tetraspanins are implicated at several stages of carcinogenesis as well as in metastasis and angiogenesis [6]. Interestingly, Vences-Catalàn and colleagues have demonstrated a dominant role of CD81 affecting metastasis and immunomodulation in cancer [7]. Targeting of CD81 may decrease fusion of metastatic colon carcinoma cells and may improve sensitivity to chemotherapeutic agents [8]. Specifically, CD81 may be important in hematopoiesis as it allows hematopoietic stem cells to re-enter to quiescence [9]. In hematologic malignancies, CD81 has mostly been studied in multiple myeloma where its expression on plasma cells is associated with worse progression free survival (PFS) and overall survival (OS) [10]. Yet, the prognostic value of CD81 has not been addressed in myeloid malignancies, such as AML. 
AML is a leading cause of leukemia-related mortality, characterized by maturation arrest and subsequent accumulation of blast cells at various stages of incomplete differentiation, and by reduced production of healthy hematopoietic elements [11]. Importantly, AML is a heterogeneous disease at both the phenotypic and molecular level with a variety of distinct genetic alterations giving rise to the disease. Currently, the combination of three days of daunorubicin and seven days of cytarabine is still accepted as the cornerstone of induction treatment allowing complete remission in younger patients in 70$80 \%$ of the cases [12]. Nevertheless, relapse still occurs in approximately half of the patients diagnosed with AML and the 5-year overall survival rate is only about $40 \%$ [11].

Over the past few years, identification of new prognostic remains important; especially those potentially refining therapeutic options. The development of prognostic markers is particularly important in AML with normal cytogenetics (CN AML) and currently, three molecular markers (NPM1- and CEBPA mutations and FLT3 internal tandem duplication (FLT3-ITD)) are used in clinical practice [13]. Prognostic value of CD81 expression in multiple myeloma and its use as a marker in minimal residual disease (MRD) in chronic lymphocytic leukemia (CLL) are well established [14]. In this study, we analyzed the association of CD81 with other biological factors and its effects on patient outcomes in AML.

\section{RESULTS}

\section{CD81 cell surface expression on normal and AML blast cells}

CD81 is homogenously expressed on physiologic myeloblasts in normal bone marrows $(\mathrm{BM})($ mean $=32 \%$; range $=21$ to $42 \% ; n=11 ;$ Figure $1 \mathrm{~A})$. In contrast, expression of CD81 on AML blasts is more heterogeneous (mean=range $=0.1$ to $100 \%, \mathrm{n}=134$ ) and significantly higher $(47 \% ; \mathrm{P}<0.001$; Figure $1 \mathrm{~B})$. Interestingly, we observed two types of AML firstly, $43 \%$ of AML with high CD81 expression (more than $50 \%$ of blasts, Figure 2A) and secondly, 31\% of AML had no CD81 expression commonly defined as less than $20 \%$ of blasts [15] (Figure 2B). While all physiologic myeloblasts showed intermediate CD81 expression, only $25 \%$ of AML were found in that range (Figure 2C).

\section{Association of CD81 with prognostic factors in AML}

A total of 134 patients were included in our study with ages ranging from 18 to 78 years. We compared patient characteristics between AML blasts positive vs. negative for CD81 expression (Table 1). Expression of CD81 was found in the majority of AML (92 of 134, $69 \%$ ), but no CD81 expression was associated with favorable characteristics (i.e., younger age, lower WBC and favorable cytogenetics). In contrast, positive CD81 expression was associated with FAB types M1 and M5 and unfavorable cytogenetics (Table 1). No difference was found for sex, hemoglobin level, platelet count, FLT3-ITD and NPM1 mutational status. CD81 positive AML tended to include more AML with FLT3-ITD mutation $(\mathrm{P}=0.06)$. AML patients with $\mathrm{CD} 81$ positive blast cells were of higher age, had higher white blood cell counts $(\mathrm{WBC})$ at diagnosis $(\mathrm{P}=0.02)$ and were more likely to have AML with intermediate or adverse-risk cytogenetics $(\mathrm{P}<0.001)$.
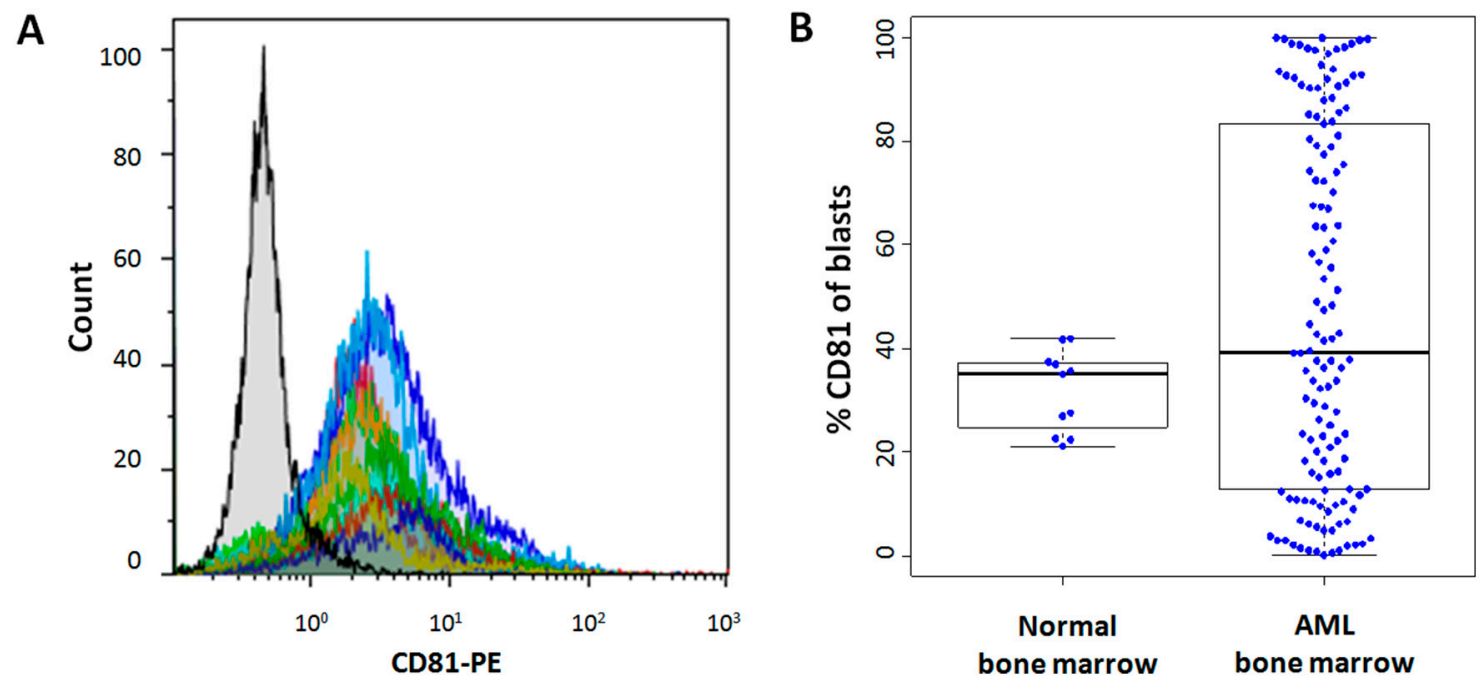

Figure 1: CD81 expression on normal and AML blast cells. A. Normal bone marrow sample overlay of mean fluorescence intensity histograms of CD81 on blast cells. Isotype control is colored in black. B. Comparison of CD81 expression on blast cells between normal bone marrow samples $(\mathrm{n}=11)$ and diagnostic bone marrow from patients with de novo AML $(\mathrm{n}=134)$. 


\section{Relevance of CD81 as a prognostic marker in} AML

At the time of analysis, we counted 40 uncensored deaths and median overall survival was 3.5 years. As expected, unfavorable cytogenetics was associated with poorer OS (hazard ratio $[\mathrm{HR}]=2.75,95 \%$ confidence interval $[\mathrm{CI}]=1.48-5.09, \mathrm{P}=0.006) . N P M 1$ mutations were significantly associated with better survival $(\mathrm{HR}=0.61$,
95\% $\mathrm{CI}=0.31-1.20, \quad \mathrm{P}=0.03)$ and FLT3-ITD mutation showed no impact on $\mathrm{OS}(\mathrm{P}=0.40)$.

CD81 expression on blast cells negatively affected EFS, OS and RFS $(\mathrm{P}<0.001)$. Multivariate analysis validated the worse prognosis of AML with CD81 expression on EFS, OS and RFS (Table 2).

CD81 expression on physiologic myeloblasts in normal BM did not exceed 40\% (Figure 1B). Furthermore, CD81 expression on AML blast cells showed a bimodal
A

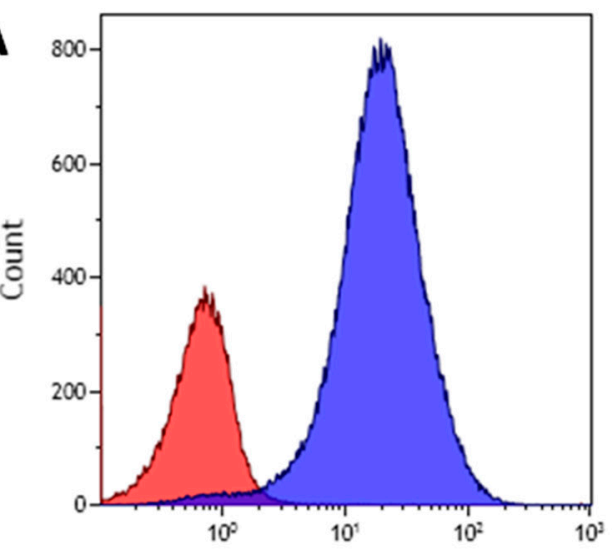

B

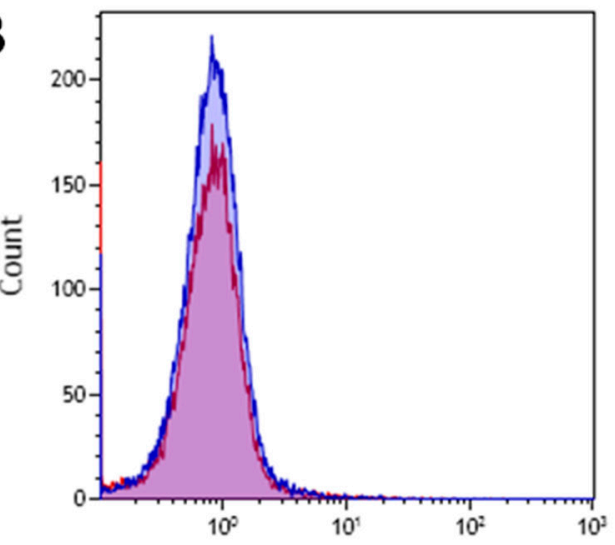

C

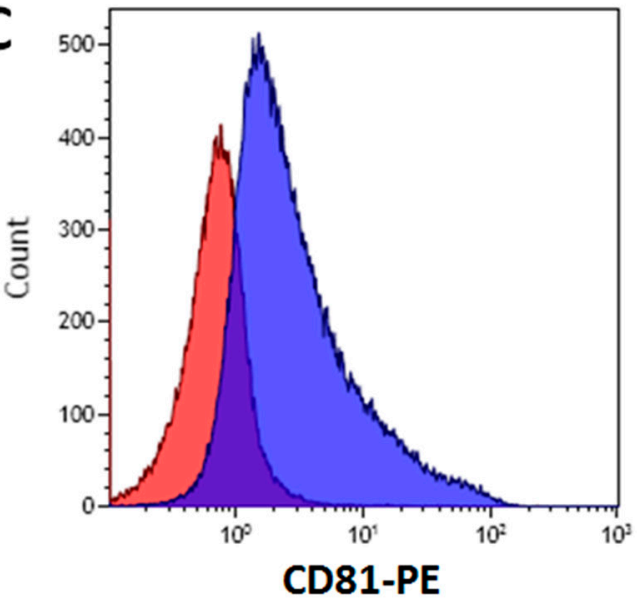

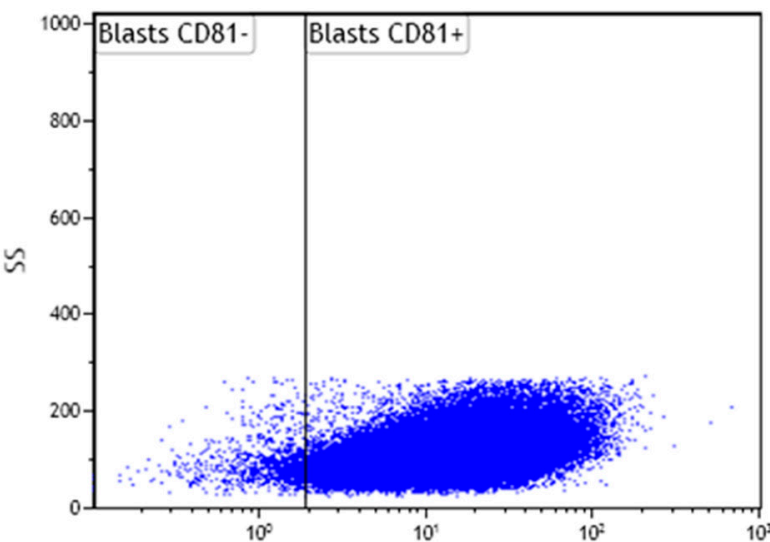
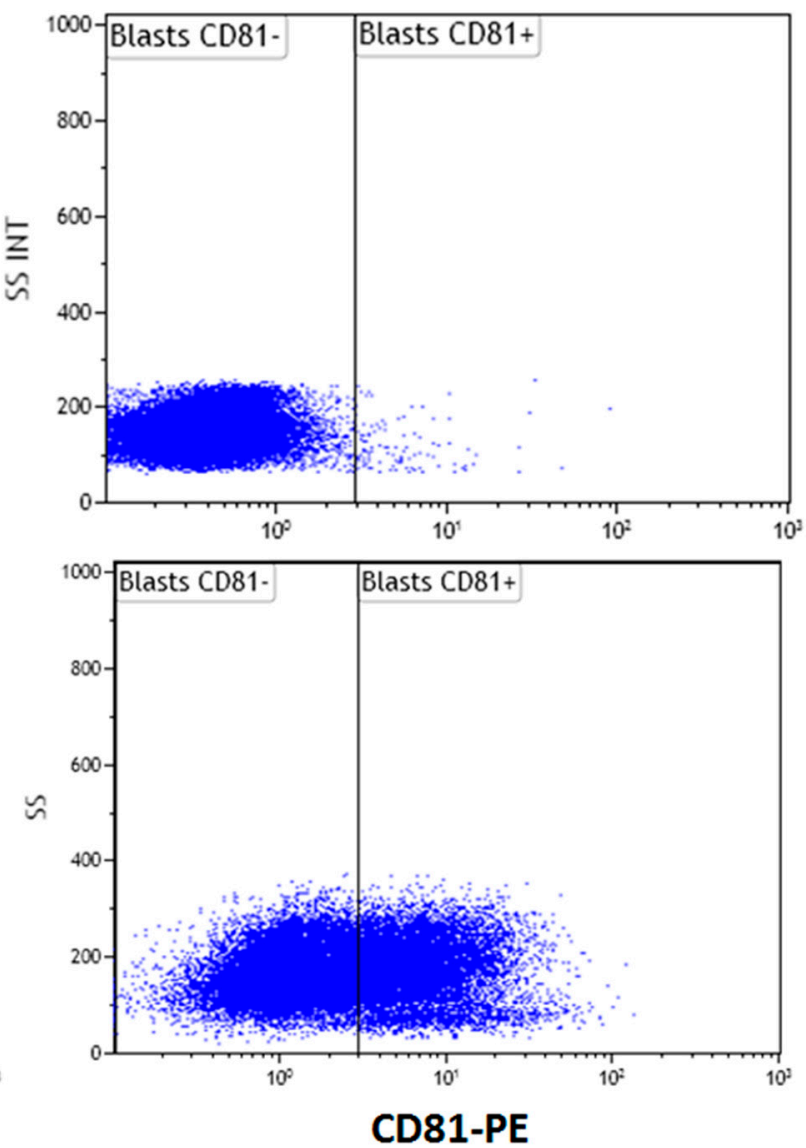

Figure 2: Primary AML have varying CD81 expression on blast cells. Representative examples of mean fluorescence intensity histograms of different types of AML according to CD81 expression: A. Example of high CD81 blast expression (CD81 $\left.{ }^{++}\right)$B. Example of negative CD81 blast expression (CD81-); $\mathbf{C}$. intermediate CD81 blast expression (CD81 ${ }^{+}$). Isotype control corresponds to the red histogram. 


\begin{tabular}{|c|c|c|c|c|}
\hline & $\begin{array}{l}\text { All patients } \\
\quad(\mathrm{n}=134)\end{array}$ & $\begin{array}{c}<20 \% \\
\text { CD81- Blasts } \\
(n=42)\end{array}$ & $\begin{array}{c}>20 \% \\
\text { CD81 }^{+} \text {Blasts } \\
(n=92)\end{array}$ & P-value \\
\hline Gender $[\mathrm{M} / \mathrm{F}]$ & $79 / 56$ & $24 / 18$ & $54 / 38$ & 0.83 \\
\hline Age $[\text { years }]^{\$}$ & $51.1 \pm 16.0$ & $46.9 \pm 16.4$ & $53.0 \pm 15.5$ & 0.04 \\
\hline WBC [G/L]* & $28(1-325)$ & $14(2-198)$ & $45(1-325)$ & 0.02 \\
\hline FAB type & & & & $<0.0001$ \\
\hline M0 & $3 \%(4 / 101)$ & $3 \%(1 / 35)$ & $4 \%(3 / 66)$ & \\
\hline M1 & $22 \%(22 / 101)$ & $14 \%(5 / 35)$ & $26 \%(17 / 66)$ & \\
\hline M2 & $28 \%(28 / 101)$ & $49 \%(17 / 35)$ & $17 \%(11 / 66)$ & \\
\hline M4 & $26 \%(26 / 101)$ & $31 \%(11 / 35)$ & $23 \%(15 / 66)$ & \\
\hline M5 & $19 \%(19 / 101)$ & $3 \%(1 / 35)$ & $27 \%(18 / 66)$ & \\
\hline M6 & $2 \%(2 / 101)$ & $0 \%(0 / 35)$ & $3 \%(2 / 66)$ & \\
\hline Hemoglobin level $[\mathrm{g} / \mathrm{dL}]^{\mathrm{s}}$ & $9.5 \pm 2.2$ & $9.5 \pm 2.3$ & $9.4 \pm 2.1$ & 0.81 \\
\hline Platelet count $[\mathrm{G} / \mathrm{L}]^{*}$ & $59(7-864)$ & $70(12-864)$ & $58(7-670)$ & 0.96 \\
\hline Cytogenetic risk, $(\mathrm{n} / \mathrm{N})$ & & & & $<0.0001$ \\
\hline Favorable & $11 \%(14 / 131)$ & $28 \%(12 / 42)$ & $2 \%(2 / 89)$ & \\
\hline Intermediate & $75 \%(98 / 131)$ & $55 \%(23 / 42)$ & $84 \%(75 / 89)$ & \\
\hline Unfavorable & $14 \%(19 / 131)$ & $17 \%(7 / 42)$ & $14 \%(12 / 89)$ & \\
\hline FLT3-ITD, $(\mathrm{n} / \mathrm{N})$ & $28 \%(36 / 129)$ & $17 \%(7 / 41)$ & $33 \%(29 / 88)$ & 0.06 \\
\hline NPM1 mut, $(\mathrm{n} / \mathrm{N})$ & $34 \%(43 / 125)$ & $28 \%(10 / 36)$ & $37 \%(33 / 89)$ & 0.32 \\
\hline
\end{tabular}

*median with range in parenthesis; ${ }^{\$}$ mean \pm SD: standard deviation; WBC: white blood cell count; M: male; F: female; NA: not applicable.

Table 2: Hazard ratio of CD81 adjusted on cytogenetic risk, age at diagnosis and NPM1+/FLT3-ITD- status

\begin{tabular}{lcc}
\hline & HR (95\% CI) & P-value \\
\hline EFS & $3.45(1.5-7.8)$ & $\mathbf{0 . 0 0 3}$ \\
OS & $4.14(1.69-10.14)$ & $\mathbf{0 . 0 0 2}$ \\
RFS & $9.46(2.66-33.71)$ & $\mathbf{0 . 0 0 0 5}$ \\
\hline
\end{tabular}

distribution with a mean of $47 \%$. Thus, we determined three groups of patients based upon CD81 expression on blast cells: CD81- $(<20 \%, \mathrm{n}=42), \mathrm{CD}^{+} 1^{+}(20$ to $50 \%$, $\mathrm{n}=34)$ and $\mathrm{CD}^{++}(>50 \%, \mathrm{n}=59)$. A worse survival was associated with a higher expression of CD81 considering OS, EFS and RFS $(\mathrm{P}<0.001)$ compared to those CD81-low (Figure 3).

Interestingly, among the NPM1 mutated patients, blasts CD81 greater than 20\% showed significant inferior $\operatorname{OS}(\mathrm{P}=0.01$, Figure $4 \mathrm{~A})$ but had no impact on EFS $(\mathrm{P}=0.24)$ or RFS $(\mathrm{P}=0.22)$. Considering ELN risk categories, subset analyses revealed a significant prognosis impact of CD81 expression for OS in ELN-favorable patients $(\mathrm{P}=0.002$, Figure $4 \mathrm{~B})$ whereas no impact was found in other categories.

\section{DISCUSSION}

AML is a heterogeneous disease and prognostic factors have become increasingly important in order to propose appropriate therapy. Currently, cytogenetic analysis is most important for AML risk classification [11] and, according to standard recommendations three risk groups are defined: favorable, intermediate 
and adverse [16]. In CN AML, prognostic tools are particularly relevant and subgroups have been defined, based on the mutational status of genes such as FLT3ITD, NPM1, and CEBPA [17]. Nevertheless, new prognostic factors are needed to better discriminate patients with AML. In this study, we evaluated the prognostic impact of CD81 expression in a cohort of 134 adult patients treated with intensive chemotherapy for AML. We found expression of CD81 in $69 \%$ of all AML cases and with a higher frequency in AML

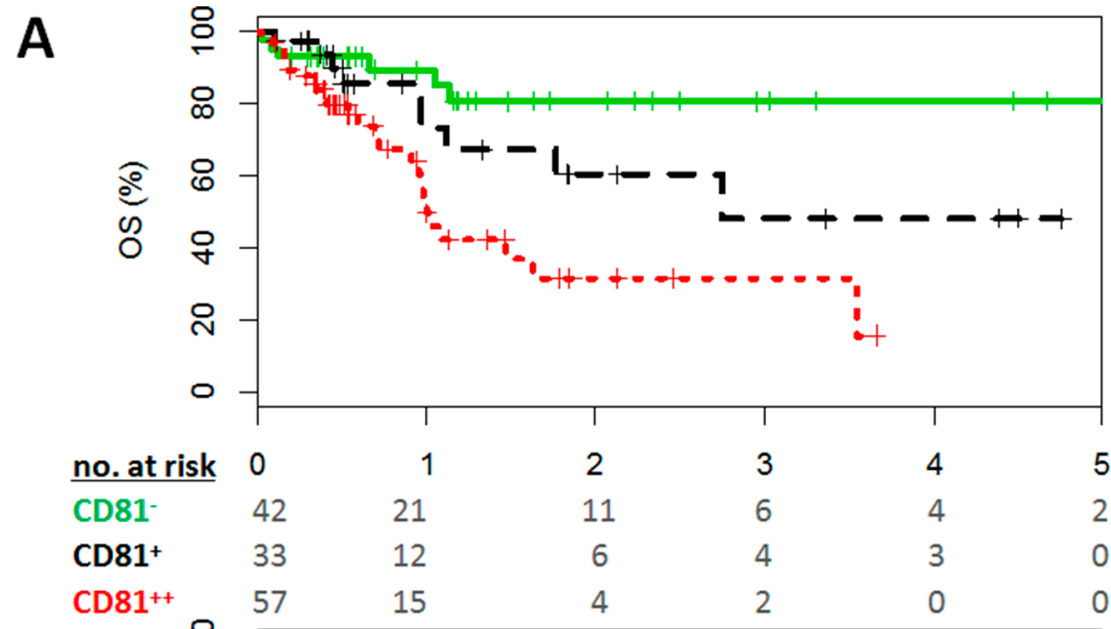

B
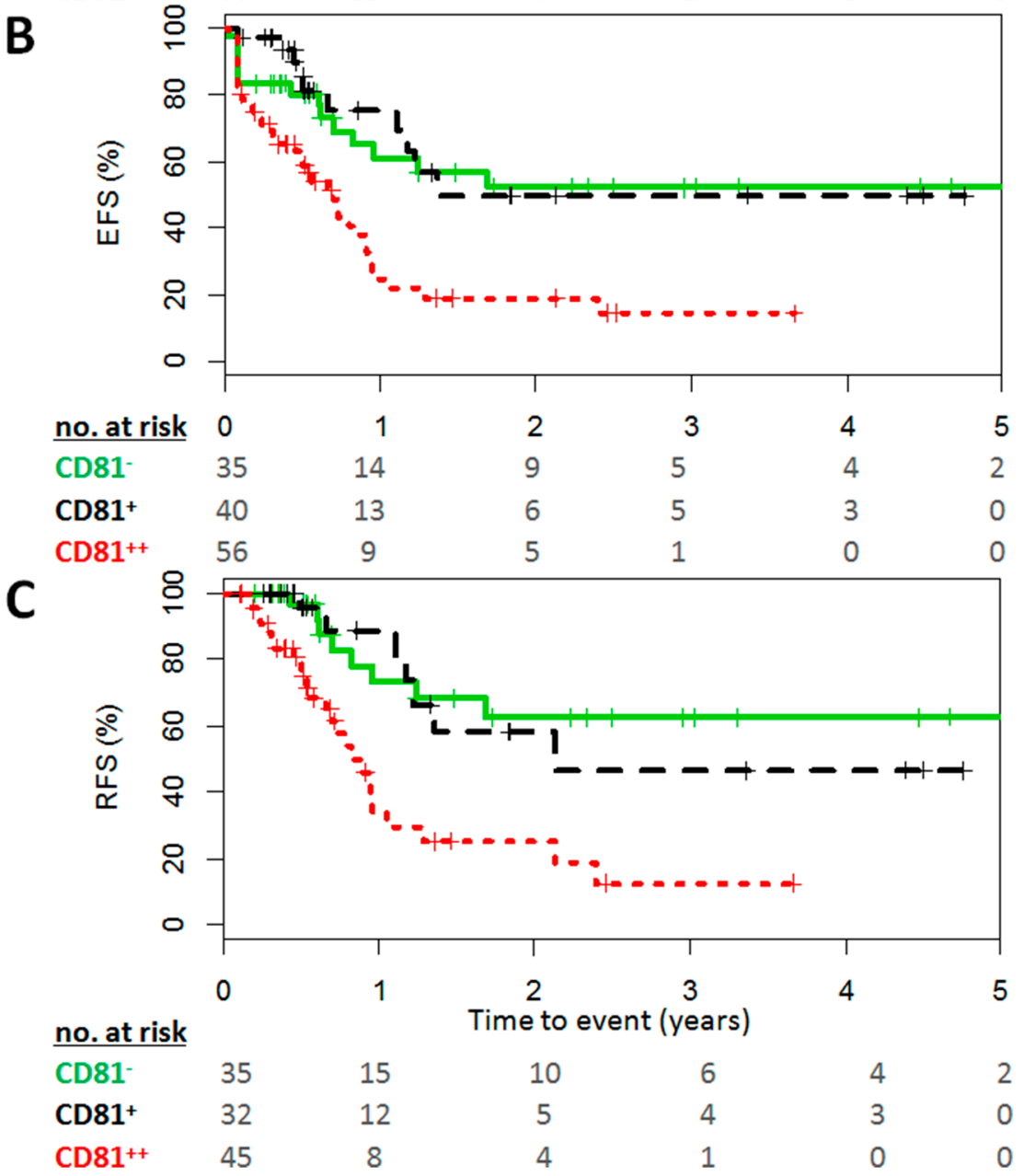

Figure 3: High CD81 expression on blast cells predicts poor outcome in AML. Survival curves of A. OS, B. EFS, C. RFS stratified by CD81 expression measured in diagnostic bone marrow of AML patients. Shown is the survival of patients with AML either $\mathrm{CD} 81^{-}$in green (less than 20\%), CD81+ in black (20 to 50\%), or CD81+ in red (greater than 50\%). Numbers at risk at each year of followup are given. P-values based on logrank test. 
with FLT3-ITD mutation $(\mathrm{P}=0.06)$. Expression of CD81 was associated with a worse clinical outcome as it negatively affected survival (EFS, OS and RFS) in univariate and multivariate analyses. Furthermore, this negative impact is even stronger with high CD81 expressing blast cells.
In multiple myeloma, detection of CD81 positive plasma cells was an independent negative prognostic factor for PFS and OS [10]. This study by Paiva et al investigated CD81 expression by MFC in 230 patients with plasma cell myeloma (PCM) and found a positive expression in $45 \%$ of the patients. The adverse impact of
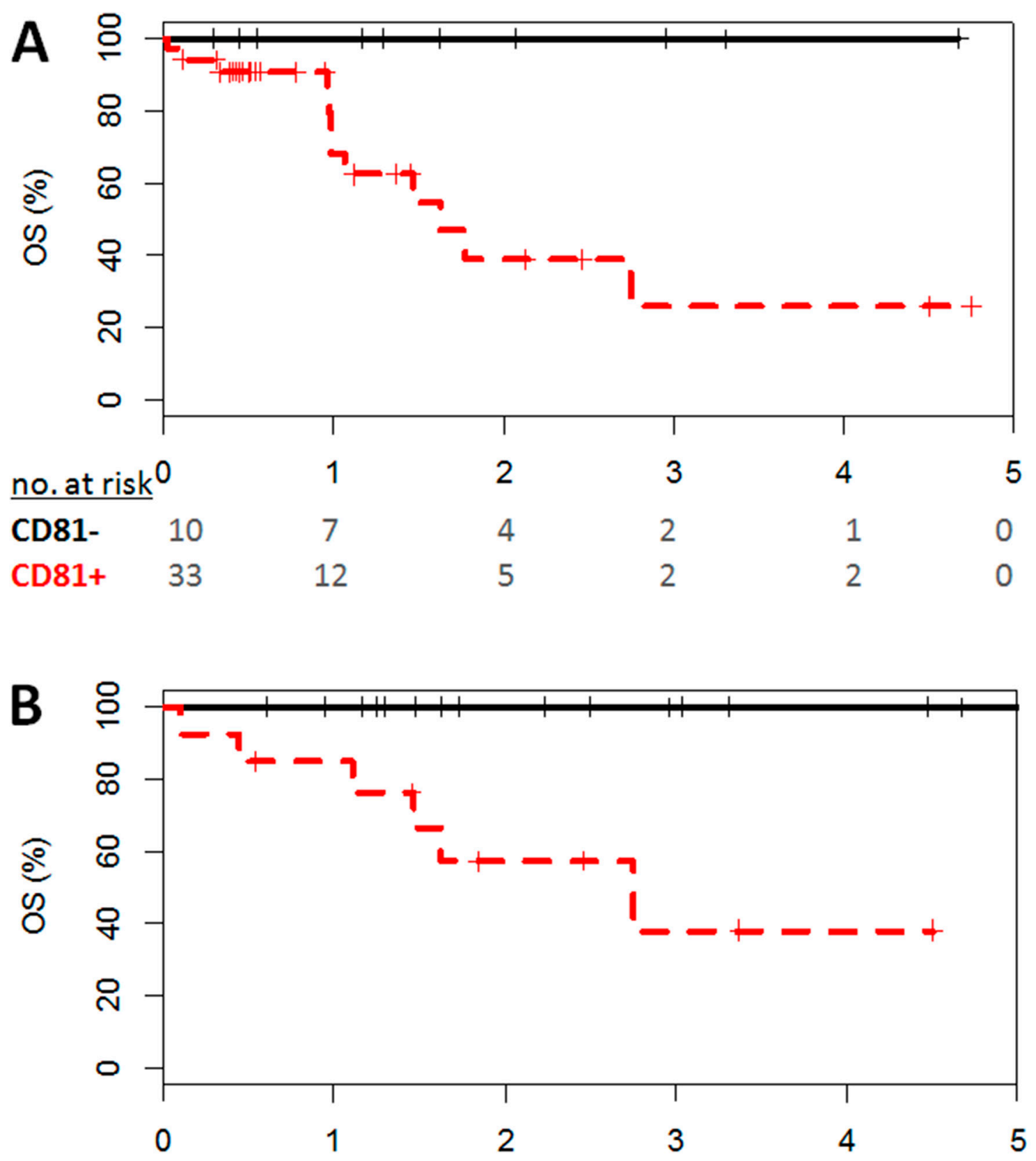

no. at risk

CD81- 18

CD81+ 13

\section{time to event (years)}

16

10

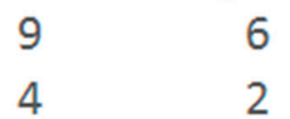

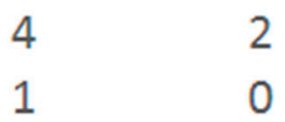

Figure 4: Effect of CD81 expression on Overall Survival in favorable-risk patients. Curve shown in black illustrates overall survival of patients with CD81- AML (less than $20 \%$ ), CD $81^{+}$in red (greater than $20 \%$ ) for A. NPM1 mutated patients and B. ELNfavorable risk group. Numbers at risk at each year of follow-up are given. P-values based on logrank test. 
CD81 was then validated in an additional 325 transplantcandidate PCM patients. Moreover, dim or negative CD81 expression was only observed in abnormal plasma cells [18]. In another study, circulating plasma cells showed significant down-regulation of integrins and activating molecules including CD81; this finding suggests a potential role in plasma cell homing for CD81 [10].

AML with more than $20 \%$ of CD81 positive blast cells showed a significant adverse prognosis for EFS, OS and RFS. In our study, these patients were older, had higher white blood count and showed an association with intermediate and adverse-risk cytogenetics compared to patients with less than $20 \%$ CD81 blasts. In ELNfavorable group, a percentage of CD81 over $20 \%$ had a significant negative impact on $\operatorname{OS}(\mathrm{P}=0.002)$ : this data is particularly interesting as it allows discriminating patients in this low-risk group. Further studies are needed to determine whether this subgroup of patients with AML will benefit from dose-intensified chemotherapy.

CD81 definitely exerts a negative impact on survival outcome in AML patients. Nevertheless, the mechanisms by which CD81 induces poor prognosis in AML are yet unknown. However, as we did not find any difference between patients with $\mathrm{CD} 81^{+}$vs. CD81- AML in achieving complete remission (CR) after remission induction therapy, the mechanism may be less likely to be chemotherapy resistance induced by CD81 expression on leukemic blasts. Though, we did note a trend for higher CD81 expression in AML of patients who did not achieve CR. Furthermore, larger cohort of patients is necessary to prove significance of CD81 expression on relapse within subgroups of AML. Furthermore, patients with CD81 positive expression presented with higher WBC at diagnosis, which may be explained by a defect in blast cell homing. Therefore, the role of CD81 in blast cell homing needs to be determined in AML, as similar effects have been described in multiple myeloma [10]. CD81 is physiologically implicated in the re-entry of hematopoietic stem cells into the quiescent state in order to control self renewal after induced proliferation. In leukemic blasts however, any alteration of this function may influence tumor dormancy and treatment outcome in patients with AML with different levels of CD81 expression.

Finally, our study provided the rational for novel therapeutic approaches targeting CD81 to be considered. Accordingly, anti-CD81 have demonstrated in vivo efficacy in HCV [19] and Plasmodium falciparum [20] infections. Future independent studies are needed to confirm prognostic impact of CD81 in AML.

\section{MATERIALS AND METHODS}

\section{Patients}

One hundred and thirty four patients with AML treated by intensive chemotherapy were included in this study. All patients were treated in the department of hematology of Lille hospital. Signed informed consent was obtained from each patient in accordance with the declaration of Helsinki. Cytogenetic risk was determined according to standard criteria [21].

Complete remission (CR) criteria were defined in agreement with the European Leukemia Net recommendation [13].

\section{Multiparameter flow cytometry (MFC)}

Diagnostic blast cells were obtained from fresh or thawed cryopreserved BM aspirates after red blood cell lysis. Of note, MFC results were not different between fresh and frozen BM cells done for five patients (data not shown). Each sample was washed twice with phosphate buffered saline and stained separately for $30 \mathrm{~min}$ at room temperature with two antibody panels. The first antibody panel contained: anti-CD36-FITC (clone FA6-152, Iotest, Beckman Coulter Inc., Brea, CA, USA ), anti-CD81-PE (clone JS24, Beckman Coulter), anti-CD33-PC5.5 (clone D3HL60.251, Iotest, Beckman Coulter), anti-CD34-AA700 (clone 581, Iotest, Beckman Coulter), and anti-CD45-KO (clone J.33, Iotest, Beckman Coulter).

The second antibody panel included: anti-CD7FITC (clone 8H8.1, Iotest, Beckman Coulter), anti-CD13PE (clone SJ1D1, Iotest, Beckman Coulter), anti-CD19ECD (clone J3-119, Iotest, Beckman Coulter), anti-CD33 PC5.5 (clone D3HL60.251, Iotest, Beckman Coulter), anti-CD117-APC (clone 104D2D1, Iotest, Beckman Coulter), anti-CD34-AA700 (clone 581, Iotest, Beckman Coulter), anti-HLA-DR-PB (clone Immu-357, Iotest, Beckman Coulter), and anti-CD45-KO (clone J.33, Iotest, Beckman Coulter). A minimum of $5 \times 10^{5}$ events were acquired.

Blast cells were gated as $\mathrm{CD} 45^{\mathrm{dim}}, \mathrm{SSC}^{\text {low }}$, $\mathrm{CD}^{+} 3^{+}$and lymphocytes (CD45 ${ }^{\text {bright }}, \mathrm{SSC}^{\text {low }}, \mathrm{CD}^{-} 3^{-}$), monocytes (CD45 $5^{\text {int/bright }}, \mathrm{SSC}^{\text {int }}, \mathrm{CD} 33^{\text {bright }}$ ) and mature myelomonocytic cells (CD45 $\left.{ }^{\text {int }}, \mathrm{SSC}^{\text {high }}, \mathrm{CD} 33^{\mathrm{dim} / \mathrm{neg}}\right)$ were excluded.

Isotype control (clone 7T4-IF5, Iotest, Beckman Coulter) was used to better define the threshold of CD81 positive-stained cells. Results are reported as percent of positive blast cells. If more than $20 \%$ of the blast population is stained, the AML sample is considered CD81 positive [22].

Measurements were performed on a Navios flow cytometer and analyzed with Kaluza software (Beckman-Coulter). The cytometer settings were daily tested for optical alignment, fluidic stability, optical detector sensitivity and standardization using adapted fluorospheres (Flowset targets $^{\mathrm{TM}}$ and Flowcheck ${ }^{\mathrm{TM}}$, Beckman-Coulter) [22]. 


\section{Statistical analysis}

The distribution of quantitative variables was verified graphically and by a Shapiro-Wilk test and the comparison between normal and AML BM sample on CD81 expression was tested using the Student t-test. Differences between patients with less than $20 \%$ of expression of CD81 and those with more than $20 \%$ of expression of CD81 on baseline quantitative variables were assessed by Student t- or Mann-Whitney U-test and qualitative variables were compared using Chi-square or Fisher Exact test.

Quantitative variables associated with either overall survival (OS), event-free survival (EFS) or relapse-free survival (RFS) were tested with the Cox model. For patients who underwent bone marrow transplantation, survival was censored at the date of transplantation, and for patients alive, survival was censored at the date of last known alive. The association between expression of CD81 and OS, EFS and RFS was adjusted by cytogenetic risk, age at diagnosis and NPM1+/FLT3-ITD- status. OS, EFS and RFS were described by the Kaplan Meier method stratified by expression of CD81 according to greater than or equal to $20 \%$, commonly defined as the bottom detection limit [15] and greater than or equal to $50 \%$, defined as CD81 over-expressing AML (i.e., top quartile).

All statistical tests were two-tailed and the significance level was set to 0.05 . Statistical analysis was performed with SAS software version 9.3 (SAS Institute, Cary, NC, USA).

\section{ACKNOWLEDGMENTS}

The authors thank all medical staff and patients participating in this study and Cécile Frimat for data management support.

\section{CONFLICTS OF INTEREST}

The authors declare no conflicts of interest

\section{GRANT SUPPORT}

This work was supported by the Ligue Contre le Cancer (North Center), ARC foundation, SIRIC Oncolille, and French National Cancer Institute.

\section{REFERENCES}

1. Oren R, Takahashi S, Doss C, Levy R, Levy S. TAPA-1, the target of an antiproliferative antibody, defines a new family of transmembrane proteins. Mol Cell Biol. 1990; 10:4007-4015.
2. Levy S. Function of the tetraspanin molecule CD81 in B and T cells. Immunol Res. 2014; 58:179-185.

3. Mattila PK, Feest C, Depoil D, Treanor B, Montaner B, Otipoby KL, Carter R, Justement LB, Bruckbauer A, Batista FD. The actin and tetraspanin networks organize receptor nanoclusters to regulate B cell receptor-mediated signaling. Immunity. 2013; 38:461-474.

4. Mittelbrunn M, Yanez-Mo M, Sancho D, Ursa A, Sanchez-Madrid F. Cutting edge: dynamic redistribution of tetraspanin CD81 at the central zone of the immune synapse in both T lymphocytes and APC. J Immunol. 2002; 169:6691-6695.

5. Charrin S, le Naour F, Silvie O, Milhiet PE, Boucheix C, Rubinstein E. Lateral organization of membrane proteins: tetraspanins spin their web. Biochem J. 2009; 420:133-154.

6. Hemler ME. Tetraspanin proteins promote multiple cancer stages. Nat Rev Cancer. 2014; 14:49-60.

7. Vences-Catalan F, Rajapaksa R, Srivastava MK, Marabelle A, Kuo CC, Levy R, Levy S. Tetraspanin CD81 promotes tumor growth and metastasis by modulating the functions of $\mathrm{T}$ regulatory and myeloid-derived suppressor cells. Cancer Res. 2015; 75:4517-4526.

8. Carloni V, Mazzocca A, Mello T, Galli A, Capaccioli S. Cell fusion promotes chemoresistance in metastatic colon carcinoma. Oncogene. 2013; 32:2649-2660.

9. Lin KK, Rossi L, Boles NC, Hall BE, George TC, Goodell MA. CD81 is essential for the re-entry of hematopoietic stem cells to quiescence following stress-induced proliferation via deactivation of the Akt pathway. PLoS Biol. 2011; 9:e1001148.

10. Paiva B, Gutierrez NC, Chen X, Vidriales MB, Montalban MA, Rosinol L, Oriol A, Martinez-Lopez J, Mateos MV, Lopez-Corral L, Diaz-Rodriguez E, Perez JJ, FernandezRedondo E, et al. Clinical significance of CD81 expression by clonal plasma cells in high-risk smoldering and symptomatic multiple myeloma patients. Leukemia. 2012; 26:1862-1869.

11. Deschler B, Lubbert M. Acute myeloid leukemia: epidemiology and etiology. Cancer. 2006; 107:2099-2107.

12. Dohner H, Weisdorf DJ, Bloomfield CD. Acute Myeloid Leukemia. N Engl J Med. 2015; 373:1136-1152.

13. Dohner H, Estey EH, Amadori S, Appelbaum FR, Buchner T, Burnett AK, Dombret H, Fenaux P, Grimwade D, Larson RA, Lo-Coco F, Naoe T, Niederwieser D, et al. Diagnosis and management of acute myeloid leukemia in adults: recommendations from an international expert panel, on behalf of the European LeukemiaNet. Blood. 2010; 115:453-474.

14. Rawstron AC, Villamor N, Ritgen M, Bottcher S, Ghia P, Zehnder JL, Lozanski G, Colomer D, Moreno C, Geuna M, Evans PA, Natkunam Y, Coutre SE, et al. International standardized approach for flow cytometric residual disease monitoring in chronic lymphocytic leukaemia. Leukemia. 2007; 21:956-964. 
15. Jaffe ES, Harris NL, Stein H, Vardiman JV. (2001). World Health Organization Classification of Tumours: Pathology and Genetics of Tumours of Haematopoietic and Lymphoid Tissues. International Agency for Research on Cancer, IARC Press, Lyon ).

16. Patel JP, Gonen M, Figueroa ME, Fernandez H, Sun Z, Racevskis J, Van VP, Dolgalev I, Thomas S, Aminova O, Huberman K, Cheng J, Viale A, et al. Prognostic relevance of integrated genetic profiling in acute myeloid leukemia. N Engl J Med. 2012; 366:1079-1089.

17. Tembhare PR, Yuan CM, Venzon D, Braylan R, Korde N, Manasanch E, Zuchlinsky D, Calvo K, Kurlander R, Bhutani M, Tageja N, Maric I, Mulquin M, et al. Flow cytometric differentiation of abnormal and normal plasma cells in the bone marrow in patients with multiple myeloma and its precursor diseases. Leuk Res. 2014; 38:371-376.

18. Paiva B, Paino T, Sayagues JM, Garayoa M, San-Segundo L, Martin M, Mota I, Sanchez ML, Barcena P, Aires-Mejia I, Corchete L, Jimenez C, Garcia-Sanz R, et al. Detailed characterization of multiple myeloma circulating tumor cells shows unique phenotypic, cytogenetic, functional, and circadian distribution profile. Blood. 2013; 122:3591-3598.
19. Ji C, Liu Y, Pamulapati C, Bohini S, Fertig G, Schraeml M, Rubas W, Brandt M, Ries S, Ma H, Klumpp K. Prevention of hepatitis $\mathrm{C}$ virus infection and spread in human liver chimeric mice by an anti-CD81 monoclonal antibody. Hepatology. 2015; 61:1136-1144.

20. Foquet L, Hermsen CC, Verhoye L, van Gemert GJ, Cortese R, Nicosia A, Sauerwein RW, Leroux-Roels G, Meuleman P. Anti-CD81 but not anti-SR-BI blocks Plasmodium falciparum liver infection in a humanized mouse model. $\mathrm{J}$ Antimicrob Chemother. 2015; 70:1784-1787.

21. Grimwade D, Walker H, Oliver F, Wheatley K, Harrison C, Harrison G, Rees J, Hann I, Stevens R, Burnett A, Goldstone A. The importance of diagnostic cytogenetics on outcome in AML: analysis of 1,612 patients entered into the MRC AML 10 trial. The Medical Research Council Adult and Children's Leukaemia Working Parties. Blood. 1998; 92:2322-2333.

22. Guery T, Roumier C, Berthon C, Renneville A, Preudhomme C, Quesnel B. B7-H3 protein expression in acute myeloid leukemia. Cancer Med. 2015; 4:1879-1883. 